\title{
$A_{2 B}$ Adenosine Receptors Regulate the Mucus Clearance Component of the Lung's Innate Defense System
}

\author{
Brett M. Rollins ${ }^{1}$, Mellisa Burn ${ }^{2}$, Ray D. Coakley ${ }^{1}$, Lucy A. Chambers ${ }^{1}$, Andrew J. Hirsh ${ }^{1}$, Mark T. Clunes ${ }^{1}$, \\ Michael I. Lethem², Scott H. Donaldson', and Robert Tarran ${ }^{1}$ \\ ${ }^{1}$ Cystic Fibrosis/Pulmonary Research and Treatment Center, The University of North Carolina, Chapel Hill, North Carolina; and \\ ${ }^{2}$ Pharmacy and Biomolecular Sciences, University of Brighton, Brighton, West Sussex, United Kingdom
}

\begin{abstract}
Adenosine (ADO) signaling is altered in both asthma and chronic obstructive pulmonary disease, and the $A_{2 B}$ adenosine receptor $\left(A_{2 B}-R\right)$ may drive pulmonary inflammation. Accordingly, it has been proposed that specific inhibition of the $A_{2 B}-R$ could treat inflammatory lung diseases. However, stimulation of the cystic fibrosis transmembrane conductance regulator (CFTR) by ADO may be crucial in permitting the superficial epithelium to maintain airway surface liquid (ASL) volume, which is required to ensure hydrated and clearable mucus. Our goal was to determine which ADO receptor (ADO-R) underlies ASL volume regulation in bronchial epithelia. We used PCR techniques to determine ADO-R expression in bronchial epithelia and used nasal potential difference measurements, Ussing chambers studies, and XZ-confocal microscopy to look at $\mathrm{Cl}^{-}$secretion and $A S L$ volume regulation. The $A_{2 B}-R$ was the most highly expressed $A D O-R$ in donor specimens of human bronchial epithelia, and inhibition of $A D O-R$ in vivo prevented activation of CFTR. $A_{2 B}-R$ was the only ADO-R detected in cultured human bronchial epithelial cells and inhibition of this receptor with specific $A_{2 B}-R$ antagonists resulted in ASL height collapse and a failure to effect ASL height homeostasis. Removal of ADO with ADO deaminase and replacement with $5^{\prime} \mathrm{N}$-ethylcarboxamide adenosine resulted in dosedependent changes in ASL height, and suggested that the cell surface (ADO) may be in excess of $1 \mu \mathrm{M}$, which is sufficient to activate $A_{2 B}-R$. $A_{2 B}-R$ are required for $A S L$ volume homeostasis in human airways, and therapies directed at inhibiting $A_{2 B}-R$ may lead to a cystic fibrosis-like phenotype with depleted ASL volume and mucus stasis.
\end{abstract}

Keywords: cystic fibrosis transmembrane conductance regulator; chloride; airway surface liquid

Altered adenosine (ADO) signaling has been associated with both asthma and chronic obstructive pulmonary disease (COPD) $(1,2)$. For example, inhaled ADO causes bronchoconstriction in individuals with asthma despite having little effect on normal subjects (3), and adenosine receptor (ADO-R) expression is altered in COPD (4). ADO is formed in airway lumens as a breakdown product of ATP $(5,6)$, and can signal through specific ADO receptors before being broken down by adenosine deaminase (ADA) $(7,8) . \mathrm{A}_{1}$ and $\mathrm{A}_{3}$ receptors signal through $\mathrm{G}_{\mathrm{i} / \mathrm{o}}$ proteins to inhibit adenylyl cyclase, and in some cases, to activate $\mathrm{Ca}^{2+}$, while $A_{2 A}$ and $A_{2 B}$ receptors signal through $G_{s}$ to activate adenylyl cyclase and raise cAMP (7). ADO can stimulate $A_{2 B}$ receptors $\left(A_{2 B}-R\right)$ to induce cytokine release from mast cells, smooth muscle, and epithelia (9). Further, ADA-null

(Received in original form December 13, 2007 and in final form February 12, 2008) This work was supported by National Institutes of Health grant HL074158 (to R.T). ATL801 was donated by Adenosine Therapeutics.

Correspondence and requests for reprints should be addressed to Robert Tarran, Ph.D., CF Center, 7125 Thurston Bowles Building, UNC-Chapel Hill, Chapel Hill, NC 27599-7248. E-mail: robert_tarran@med.unc.edu

This article has an online supplement, which is accessible from this issue's table of contents at www.atsjournals.org

Am J Respir Cell Mol Biol Vol 39. pp 190-197, 2008

Originally Published in Press as DOI: 10.1165/rcmb.2007-04500C on March 26, 2008

Internet address: www.atsjournals.org

\section{CLINICAL RELEVANCE}

We find that $\mathrm{A}_{2 \mathrm{~B}}$ receptors are physiologically active in nondiseased airways and regulate airway surface liquid volume homeostasis. Inhibition of these receptors is therefore not recommended in the treatment of chronic lung disease.

mice, which exhibit raised airway ADO levels, displayed elevated IL-13 levels and chronic airway remodeling that can be reversed by specific $A_{2 B}-R$ blockade $(10,11)$. Thus, inhibition of $\mathrm{A}_{2 \mathrm{~B}}-\mathrm{R}$ has been proposed as a potential therapy for treating chronic airway diseases $(12,13)$.

Despite data showing that ADO can be pro-inflammatory, $\mathrm{ADO}$ is also required for maintenance of the mucus clearance component of the innate lung defense system (14). Airway surface liquid (ASL) height must be greater than or equal to $7 \mu \mathrm{m}$ to keep mucus away from the epithelial surface to allow cilia to beat and maintain efficient mucus transport. This complex process is in part mediated by $\mathrm{ADO}$, which activates cystic fibrosis transmembrane conductance regulator (CFTR)mediated $\mathrm{Cl}^{-}$secretion in human nasal epithelia in vivo and directly regulates both CFTR $\mathrm{Cl}^{-}$channels and the epithelial $\mathrm{Na}^{+}$channel (ENaC) in cultured airways (15-17). Removal of ADO, inhibition of ADO-R, or a lack of CFTR (i.e., in CF airway epithelia) all result in a failure to regulate ASL height to $7 \mu \mathrm{m}$ and result in a decrease in ASL height to CF-like levels (i.e., $\sim 3 \mu \mathrm{m})(5,18)$. This ASL depletion causes mucus stasis and is predicted to cause mucus plugging (19). Thus, there appears to be a requirement for ADO to be present in the ASL to activate CFTR and sufficiently hydrate the mucus layer. The relatively high levels of $\mathrm{ADO}$ required to activate $\operatorname{CFTR}(\geqslant 1 \mu \mathrm{M})$ suggest that CFTR is regulated by the $A_{2 B}-R$. However, ASL ADO is typically sub- $\mu \mathrm{M}$, as measured by lavage (20), which has led investigators to suggest that the $\mathrm{A}_{2 \mathrm{~B}}-\mathrm{R}$, which has an $\mathrm{EC}_{50}$ of approximately $2 \mu \mathrm{M}$, is not physiologically active (12).

Since inhibition of $\mathrm{A}_{2 \mathrm{~B}}-\mathrm{R}$ has potential benefits with regard to reducing airway inflammation, it has become an attractive therapeutic target for the treatment of chronic lung disease. However, if $\mathrm{A}_{2 \mathrm{~B}}-\mathrm{R}$ also regulates CFTR, then inhibition of this receptor may also induce ASL volume depletion. Thus, we set out to determine which ADO-R are expressed in the superficial airway epithelium and whether specific $A_{2 B}-R$ blockade could inhibit ASL volume homeostasis.

\section{MATERIALS AND METHODS}

Please see the online supplement for more detailed methods, including the lists of primers and solutions/chemicals used.

Laser Capture Microscopy, qPCR, and Primer Sequences

Normal human bronchi obtained immediately after lung transplant surgery were snap-frozen in OCT (Tissue-Tek, The Netherlands), sectioned at $8 \mu \mathrm{m}$, and the sections placed on Leica PEN slides (Leica, Bannockburn, IL). Ciliated cells were identified by light microscopy 
and laser captured onto HS LCM caps (Arcturus, Sunnyvale, CA) and RNA was isolated using PicoPure RNA Isolation Kit (Arcturus). RNA was converted to cDNA and measured by LightCycler (Roche, Indianapolis, IN), as described previously (21).

\section{In Vivo Nasal Potential Differences}

The study protocol was approved by the UNC Committee on the Protection of Rights of Human Subjects. Mean age was $27 \pm 3$ years $(n=6)$. Nasal potential difference $(\mathrm{PD})$ was measured between a subcutaneous reference electrode and an exploring electrode placed against the inferior turbinate as previously described (22). For each subject, the PD was recorded in both nostrils and an average taken.

\section{Measurement of In Vivo Nasal ASL ADO}

Lavage of $5 \mathrm{ml} 37^{\circ} \mathrm{C}$ saline was instilled into each naris over a period of 30 seconds in $\mathrm{a} 37^{\circ} \mathrm{C}$ humidified room and retrieved over 15 seconds and placed on ice. ADO derivatization was performed as previously described (23).

\section{Isolation and Culture of Human Bronchial Epithelia}

Human excess donor tissue was obtained at the time of lung transplantation from portions of main stem or lumbar bronchi under a protocol approved by the UNC Medical School IRB, and cells were harvested by enzymatic digestion seeded directly as primary cultures on 12-mm Transwell Clear or Snapwell inserts (Costar, Lowell, MA) in modified BEGM media under air-liquid interface conditions, and studied when fully differentiated (2-5 wk) as described previously (24).

\section{Ussing Chamber Measurements of Transepithelial PD}

Human bronchial epithelial cells (HBECs) were mounted in Ussing chambers as previously described (25).

\section{Confocal Microscopy Measurements of ASL Height}

ASL was stained with either FITC or Texas Red-dextran and measured using a Leica SP5 inverted confocal microscope with a $\times 63$ glycerol immersion lens as previously described (21).

\section{Intracellular $\mathrm{Ca}^{2+}$ and cAMP Measurements}

HBECs were loaded with free Fura-2 by incubation in $2.5 \mu \mathrm{M}$ Fura-2/ $\mathrm{AM}$ at $37^{\circ} \mathrm{C}$ for 45 minutes. Cells were then washed and the fluorescence intensity ratio (excitation $340 / 380$, emission $>450 \mathrm{~nm}$ ) was collected as previously described (18).

cAMP was measured as previously described (23) by enzyme immunoassay (Sigma-Aldrich, St. Louis, MO). Cellular cAMP was normalized to protein as determined by the BCA method (Pierce Biotechnology Inc., Rockford, IL).

\section{Statistics}

All data are presented as the mean $\pm \mathrm{SE}$ for $\mathrm{n}$ experiments. For in vitro experiments, cultures derived from three or more patients were used. Differences between means were tested for statistical significance using paired or unpaired $t$ tests or their nonparametric equivalent as appropriate to the experiment. From such comparisons, differences yielding $P \leqslant 0.05$ were judged to be significant.

\section{RESULTS}

\section{In Vivo Expression of ADO-R}

CFTR is present in ciliated cells in the surface epithelia (26) and functionally, these cells are thought to be a major source of transepithelial $\mathrm{Cl}^{-}$secretion (27). To see which ADO-R are expressed in the superficial epithelium in vivo, we performed laser capture to remove groups of ciliated cells from freshly frozen sections of normal human bronchial epithelia. Figure 1A shows a typical region obtained by laser capture. mRNA samples from ciliated cells were then reverse-transcribed to make cDNA for real time PCR analysis. $\mathrm{A}_{1}$ receptors were not detected in ciliated cells from any of the donors (Figure $1 \mathrm{~B}$ ). The $\mathrm{A}_{2 \mathrm{~B}}$ receptor was the most highly expressed, with $\mathrm{A}_{2 \mathrm{~A}}$ and $\mathrm{A}_{3}$ receptors being approximately 3- to 5-fold less abundant (Figure 1B).

\section{ADO-R Blockade Inhibits CFTR Activation In Vivo}

Using the nasal PD technique, Hentchel-Franks and colleagues demonstrated that ADO activates CFTR-mediated $\mathrm{Cl}^{-}$secretion in vivo (15). To test whether ADO-R antagonism would prevent activation of CFTR-mediated $\mathrm{Cl}^{-}$secretion in vivo, we measured the change in nasal PD in six normal subjects after $\mathrm{ADO}$ addition. Since we cannot add specific $\mathrm{A}_{2 \mathrm{~B}}-\mathrm{R}$ antagonists in vivo, we added the nonspecific $\mathrm{ADO}-\mathrm{R}$ antagonist caffeine at $30 \mu \mathrm{M}$, which is close to the $\mathrm{IC}_{50}$ for the $\mathrm{A} 2 \mathrm{~B}-\mathrm{R}$ but is predicted to be too low to affect phosphodiesterase activity $(28,29)$.

After amiloride addition to inhibit $\mathrm{ENaC}$, we added a low $\mathrm{Cl}^{-}$mucosal solution with $10 \mu \mathrm{M}$ ADO to generate a maximal gradient for $\mathrm{Cl}^{-}$secretion and stimulate A2B-R. This caused an approximately $20 \mathrm{mV}$ hyperpolarization of the $\mathrm{PD}$, which is indicative of activation of significant $\mathrm{Cl}^{-}$secretion (Figure 2A). In the same subjects, addition of $30 \mu \mathrm{M}$ caffeine to the low $\mathrm{Cl}^{-}$ Ringer reduced this response by $75 \%$, suggesting that ADO-R blockade attenuates CFTR-mediated $\mathrm{Cl}^{-}$secretion (Figure 2A).

Isoproterenol (ISO) stimulates CFTR-mediated $\mathrm{Cl}^{-}$secretion via $\beta_{2}$ adrenergic receptors and, in our hands, stimulated $\mathrm{Cl}^{-}$secretion to a degree similar to ADO (Figure 2B) (27). However, the ISO response was not altered by caffeine, suggesting that caffeine acted specifically to inhibit A2B-R (Figure 2B).

To test whether in vivo nasal ADO levels are sufficient to activate CFTR-mediated $\mathrm{Cl}^{-}$secretion, we next collected nasal ASL by lavage. During tidal breathing, nasal ASL ADO was $740 \pm 78 \mathrm{nM}$ ( $n=8$ subjects), suggesting that $\mathrm{A}_{2 \mathrm{~B}}-\mathrm{R}$ is approximately $25 \%$ active in nasal epithelia in vivo.

\section{The $A_{2 B}-R$ Is the Most Highly Expressed ADO-R in Airway} Epithelial Cultures

We have previously demonstrated that ADO addition can acutely stimulate ASL secretion in normal HBECs (21). To
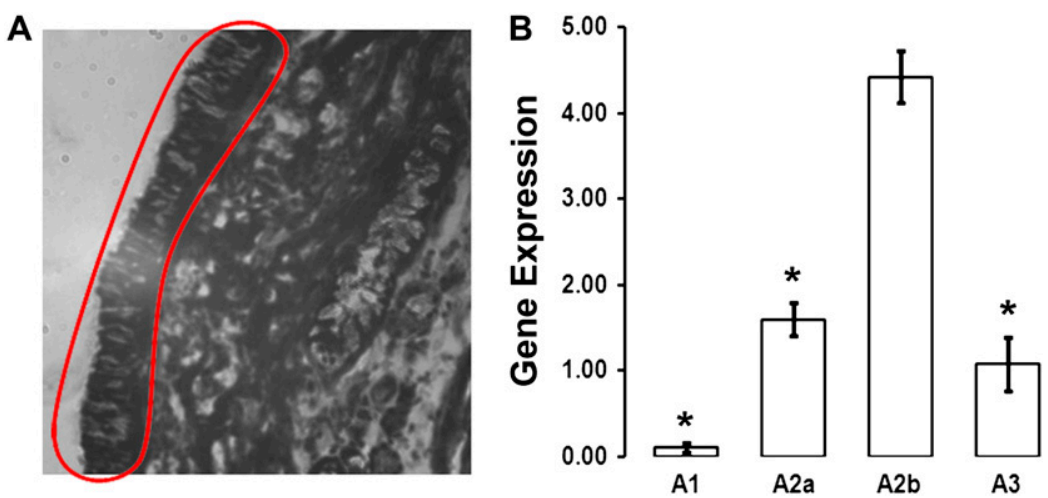

Figure 1. Adenosine (ADO) receptor (ADO-R) expression in native human bronchial epithelia. $(A)$ Ciliated cell-rich region of human bronchial epithelium dissected and trapped by laser capture (red circle). (B) Real-time qPCR analysis of ADO-R expression of tissue shown in A. Data are from four individual donors. Gene expression is relative to GAPDH. Data shown as mean \pm SEM. ${ }^{*} P<0.05$ different from $A_{2 B}-R$ expression. 

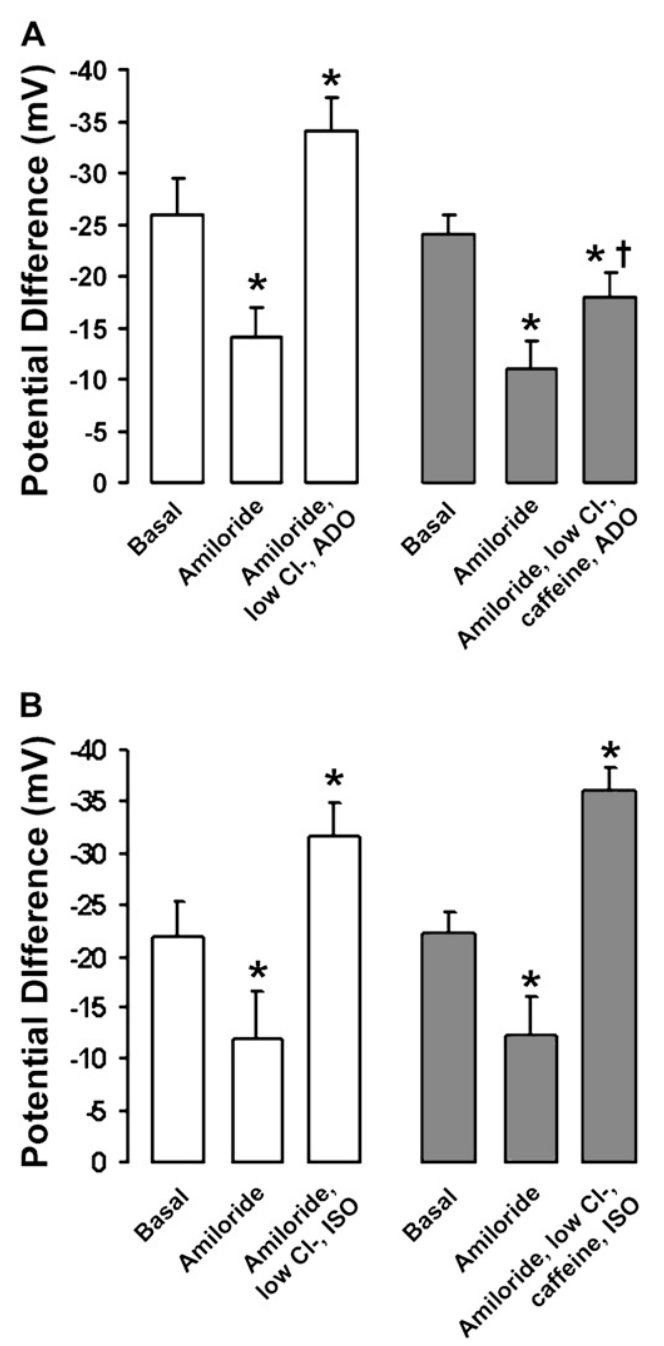

Figure 2. ADO-R blockade inhibits cystic fibrosis transmembrane conductance regulator (CFTR) activation in vivo. (A) Bar graph of mean nasal potential differences (PDs) under basal conditions and after sequential exposure to $100 \mu \mathrm{M}$ amiloride followed by amiloride with a low $\mathrm{Cl}^{-}$Ringer and $10 \mu \mathrm{M}$ ADO (open bars), or amiloride with a low $\mathrm{Cl}^{-}$Ringer, $10 \mu \mathrm{M}$ ADO, and $30 \mu \mathrm{M}$ caffeine (shaded bars) ( $n=6$ subjects). (B) Mean nasal PDs under basal conditions, with amiloride and amiloride with a low $\mathrm{Cl}^{-}$Ringer and $10 \mu \mathrm{M}$ isoproterenol (ISO; open bars) and with ISO and $30 \mu \mathrm{M}$ caffeine (shaded bars) ( $n=5$ subjects). Data shown as mean \pm SEM. ${ }^{*} P<0.05$ different from basal PDs. ${ }^{\dagger} P<$ 0.05 different from ADO alone.

identify which ADO-R were expressed in our HBEC system, we first performed a PCR analysis on RNA isolated from HBECs, which represent a ciliated cell-rich population. Similar to bronchial ciliated cells in vivo (Figure 1), A1 receptors were not expressed in HBECs (Figure 3A). However, unlike ciliated cells in vivo or positive controls from whole lung and brain, $\mathrm{A}_{3}$ ADO receptors could not be detected in HBECs from three separate donors (two male, one female), and $\mathrm{A}_{2 \mathrm{~A}}$ receptors were barely detectable (Figure $3 \mathrm{~A}$ ). In contrast, $\mathrm{A}_{2 \mathrm{~B}}$ receptors appeared to be consistently expressed in cultures from all three donors (Figure 3A).

The PCR study indicated that the $\mathrm{A}_{2 \mathrm{~B}}-\mathrm{R}$ was the most highly expressed ADO-R in HBECs. $A_{2 B}-R$ is the least sensitive of the $\mathrm{ADO}-\mathrm{R}$ to $\mathrm{ADO}$, with an $\mathrm{EC}_{50}$ of approximately $2 \mu \mathrm{M}$ (7). To determine the $\mathrm{EC}_{50}$ for $\mathrm{ADO}$ activation of $\mathrm{Cl}^{-}$secretion in our culture system, we measured the transepithelial potential dif- ference $\left(\mathrm{V}_{\mathrm{t}}\right)$ under open circuit conditions in airway cultures mounted in Ussing chambers in the presence of mucosal amiloride and a mucosal low $\mathrm{Cl}^{-}$solution. Under these conditions, ADO produced a dose-dependent increase in PD with an $\mathrm{EC}_{50}$ of $1.6 \pm 0.09 \mu \mathrm{M}$, which is consistent with activation of $\mathrm{A}_{2 \mathrm{~B}}-\mathrm{R}$ (Figure $3 \mathrm{~B}$ ).

To confirm that the $A_{2 B}$ receptor underlay the increase in ASL height in response to ADO, we next measured ASL height by XZ confocal microscopy before, and 10 minutes after, the addition of approximately $300 \mu \mathrm{M}$ ADO or its analogs suspended as dry powders in perfluorocarbon, so as not to disturb the ASL by addition of a liquid vehicle (Figure 3C). (N.B.: for this study, all cultures were pretreated with aprotinin to inhibit $\mathrm{ENaC}$ and hyperpolarize the apical membrane to provide a favorable gradient for $\mathrm{Cl}^{-}$secretion [21].) Consistent with $\mathrm{A}_{2 \mathrm{~B}}-\mathrm{R}$ being the most highly expressed ADO-R in the HBECs, we observed full stimulation of ASL secretion with $5^{\prime} \mathrm{N}$ ethylcarboxamide adenosine (NECA) and partial stimulation with CGS21680. In contrast, the $\mathrm{A}_{1}-\mathrm{R}$ and $\mathrm{A}_{3}-\mathrm{R}$ agonists IBMECA and R-PIA failed to induce ASL secretion (Figure 3C).

Pretreatment of the mucosal surface with the non-specific ADO-R inhibitor caffeine, the $\mathrm{A}_{2}-\mathrm{R}$ inhibitor alloxazine, or the $\mathrm{A}_{2 \mathrm{~B}}$-specific inhibitor ATL801 (30) before ADO addition abolished ADO-mediated ASL secretion, providing further evidence that $\mathrm{A}_{2 \mathrm{~B}}-\mathrm{R}$ underlies ADO-mediated ASL secretion, while antagonists of the $A_{1}, A_{2 A}$, and $A_{3}$ receptors (DPCPX, ZM241385, and MRS1191, respectively) (31-33) had no effect on secretion (Figure 3D).

To confirm that inhibition of CFTR attenuates ASL volume secretion, we pretreated HBECs with the CFTR inhibitor glibenclamide $(10 \mu \mathrm{M})(34)$, which directly inhibits CFTR and ASL secretion in response to ADO (Figure 3D). In contrast, DIDS $(100 \mu \mathrm{M})$, which inhibits the $\mathrm{Ca}^{2+}$-activated $\mathrm{Cl}^{-}$channel (35) had no effect on ADO-mediated ASL secretion (Figure 3D).

\section{The Effect of ADO on HBEC Cell Signaling}

Stimulation of $A_{1}-R, A_{2 B}-R$, and $A_{3}-R$ has previously been shown to increase $\mathrm{Ca}^{2+}{ }_{i}$ via linkage of these receptors to $\mathrm{G}_{\mathrm{q}}(7$, 36). However, $100 \mu \mathrm{M}$ ADO had no effect on intracellular $\mathrm{Ca}^{2+}$, suggesting that ADO did not stimulate $\mathrm{G}_{\mathrm{q}}$ in bronchial epithelia (Figure 4A). To confirm that our system was operating normally, we also exposed the HBECs to ATP, which caused an approximately 3 -fold increase in the Fura 2 emission ratio (Figure 4A). In contrast, stimulation of HBECs with $30 \mu \mathrm{M}$ ADO caused a robust increase in cAMP that was attenuated by alloxazine addition (Figure $4 \mathrm{~B}$ ), suggesting that $\mathrm{HBEC} \mathrm{A}_{2 \mathrm{~B}}-\mathrm{R}$ are coupled to $\mathrm{G}_{\mathrm{s}}$ to raise intracellular cAMP.

\section{ADO Acts as a Sensor to Mediate ASL Volume Homeostasis via $A_{2 B}$ Receptors}

Normal airway epithelia spontaneously regulate ASL height to greater than or equal to $7 \mu \mathrm{m}$, although the mechanism whereby ASL volume status is signaled to the epithelia is not fully understood (37). We have hypothesized that the concentration or dilution of molecules in the ASL such as ADO is crucial in setting the ASL to appropriate heights (37). To test whether $\mathrm{ADO}$ acts as a concentration-dependent signal to regulate ASL volume, we pretreated cultures with ADA to remove any exogenous ADO. Since ADO is rapidly hydrolyzed on airway surfaces, we dosed cultures with a test "ASL" containing different concentrations of NECA, a poorly hydrolyzed analog of ADO. To confirm that NECA was not hydrolyzed by ADA, we added $1 \mathrm{unit} / \mathrm{ml} \mathrm{ADA}$ and $1 \mu \mathrm{M}$ NECA to $1 \mathrm{ml}$ Ringer solution for 1 hour, and then measured [NECA] by high-performance liquid chromatography, following etheno-derivatization of NECA (see 
A

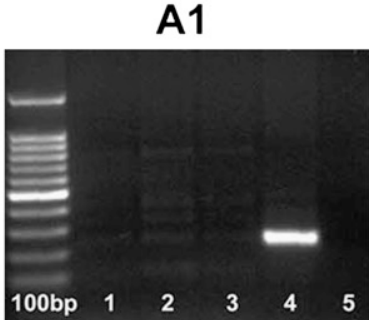

A2B

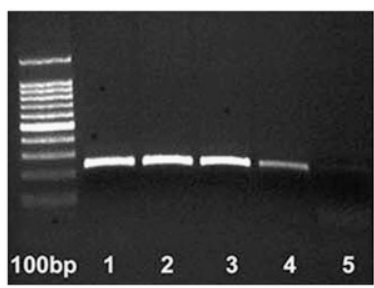

A2A

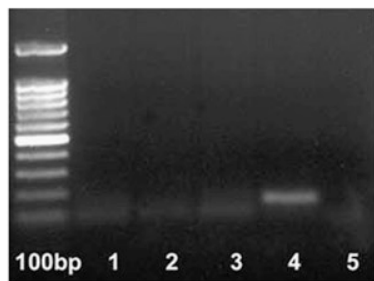

A3

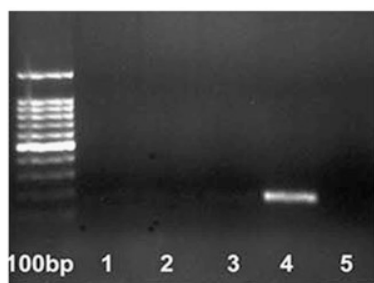

B

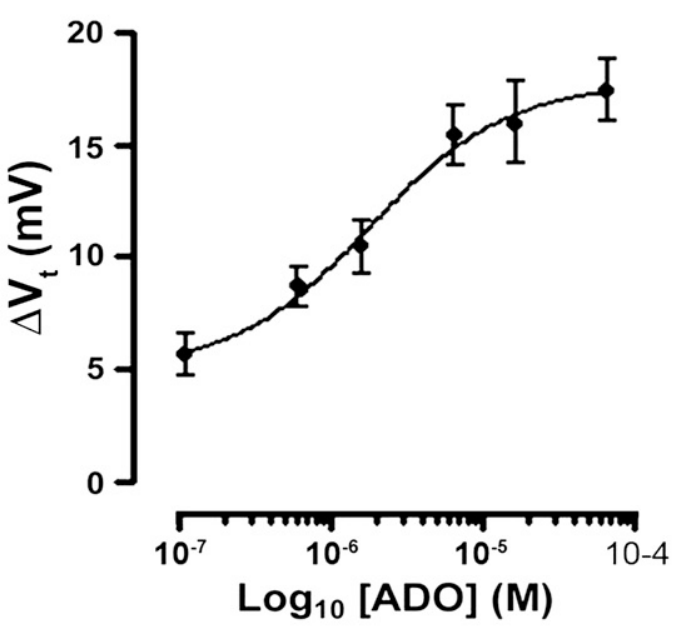

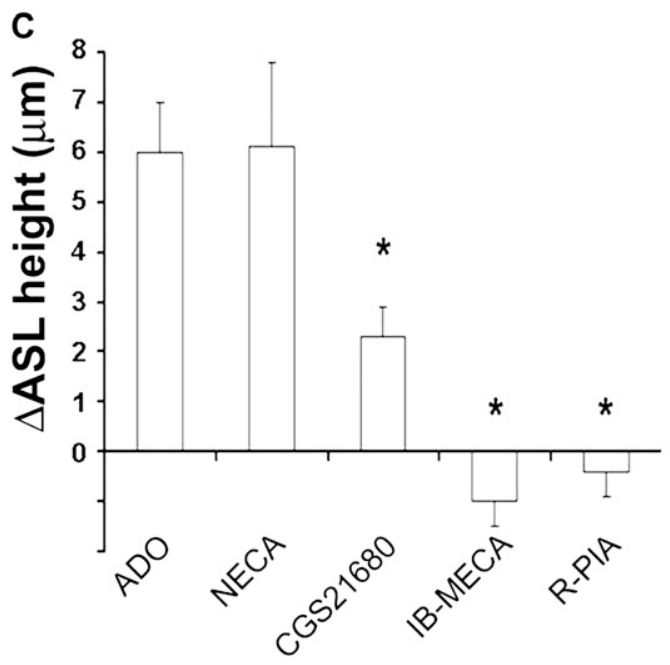

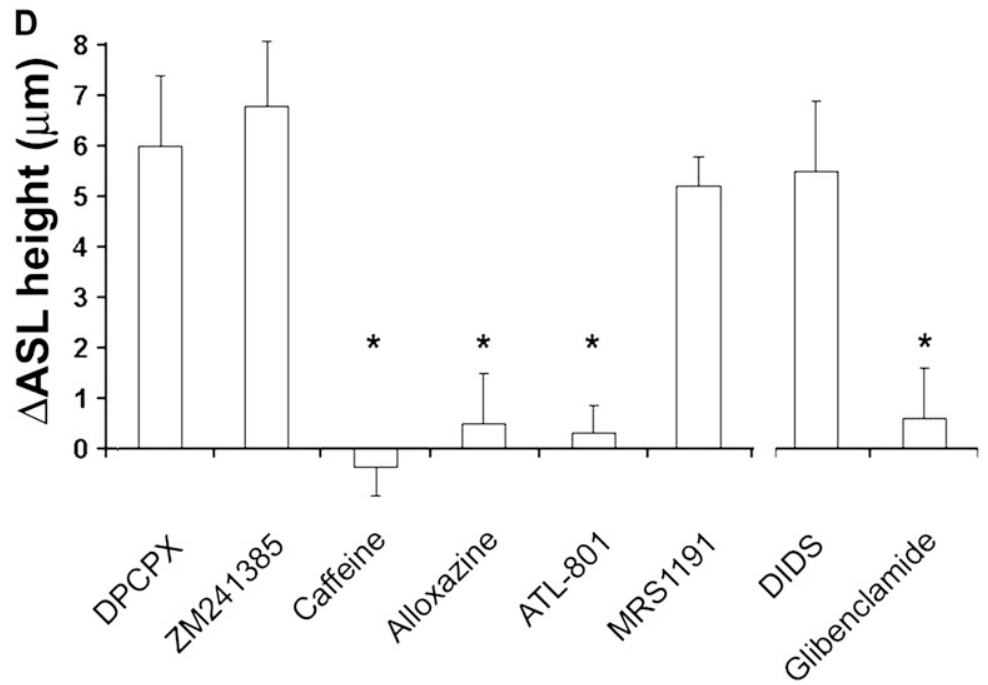

Figure 3. The $A_{2 B}$ ADO-R is the main ADO-R subtype expressed in human bronchial epithelial cells (HBECs). ( $A$ ) Banding patterns obtained after RTPCR of CDNAs from normal HBECs using primers against the ADO-Rs shown. Lanes 1-3 show bands from three different donors against ADO-Rs as described. Lane 4 is a positive control $\left(A_{1}\right.$, whole brain; $A_{2 A}, A_{2 B}, A_{3}$, whole lung) and lane 5 shows the respective primers run in water. All ladders are $100 \mathrm{bp}$. The identity of the $A_{2 B}$ bands were confirmed by sequencing. (B) Dose-dependent increase in transepithelial potential difference $\left(V_{t}\right)$ after mucosal ADO addition. HBECs were mounted in Ussing chambers and $V_{t}$ was measured under open circuit conditions. All measurements were made in the presence of $10^{-4} \mathrm{M}$ amiloride and with mucosal $\mathrm{Cl}^{-}$being replaced with gluconate to maximize the gradient for $\mathrm{Cl}^{-}$efflux. Under these conditions, the baseline PD was $-5.9 \pm 2.1 \mathrm{mV}$. All $n=6$. (C) Changes in airway surface liquid (ASL) height measured by XZ confocal microscopy 10 min post-addition of ADO and its analogs as dry powders suspended in perfluorocarbon (final concentration $\sim 200 \mu \mathrm{M}$ ). All $n=6$. $(D)$ Left, changes in ASL height 10 minutes after ADO addition in the presence of DPCPX, ZM241385, alloxazine, or MRS1191 (all pre-added at $10^{-6}$ M), caffeine $\left(3 \times 10^{-5} \mathrm{M}\right)$, and ALT801 $\left(2 \times 10^{-7} \mathrm{M}\right)$. All $n=6-8$. Right, changes in ASL height 10 minutes after ADO addition in the presence of glibenclamide or DIDS (both added at $2 \times 10^{-4} \mathrm{M}$ ). All $n=6$. (N.B., for $C$ and $D$, all cultures were pretreated with $1 \mathrm{U} / \mathrm{ml}$ aprotinin to inhibit ENaC before $\mathrm{P} 1$ agonist addition.) Data shown as mean \pm SEM. ${ }^{*} P<0.05$ as compared with $\mathrm{ADO}$ alone.

Materials and Methods). After 1 hour, the NECA concentration was unchanged, confirming that it is resistant to hydrolysis by ADA. HBECs exposed to ADA with $10 \mathrm{nM}$ NECA were unable to regulate ASL height (Figures 5A and 5B). In contrast, addition of $100 \mathrm{nM}$ NECA to the test ASL resulted in a constant ASL height over 8 hours (i.e., neither absorption nor secretion), while $1 \mu \mathrm{M}$ NECA addition caused an increase in ASL height over 8 hours that was almost identical to the control cultures, which did not have ADA/NECA and were unable to autoregulate ASL height (Figures 5A and 5B).

To test that there was an absolute requirement for $A_{2 B}-R$ to regulate this system, we added $30 \mu \mathrm{l}$ PBS to HBEC surfaces containing fluorescent dextran and ADO-R antagonists. We then aspirated excess ASL to preset ASL height at approximately $5 \mu \mathrm{m}$ and measured ASL height by XZ confocal microscopy 2 and 8 hours after exposure to a panel of ADO-R antagonists. In control cultures, ASL height was readjusted to approximately $7 \mu \mathrm{m}$ within 2 hours, a height that was maintained for a further 6 hours (Figure 6). Cultures pretreated with the $\mathrm{A}_{2}-\mathrm{R}$ antagonist alloxazine or the $\mathrm{A}_{2 \mathrm{~B}}-\mathrm{R}$-specific antagonist ATL801 were unable to regulate ASL height, consistent with a lack of $\mathrm{Cl}^{-}$secretion in the absence of ADO (Figures 6A and $6 \mathrm{~B})$. In contrast, cultures exposed to the $\mathrm{A} 1, \mathrm{~A} 2 \mathrm{~A}_{\mathrm{A}}$, and $\mathrm{A} 3$ receptor antagonists DPCPX, ZM241385, and MRS1191 (all at $10 \mu \mathrm{M}$ ) maintained ASL height regulation over 8 hours that was indistinguishable from control cultures (Figures 6C and 6D). 
A

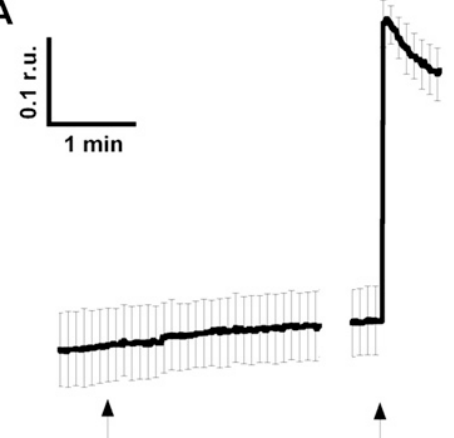

$100 \mu \mathrm{M}$ ADO

$100 \mu \mathrm{M}$ ATP

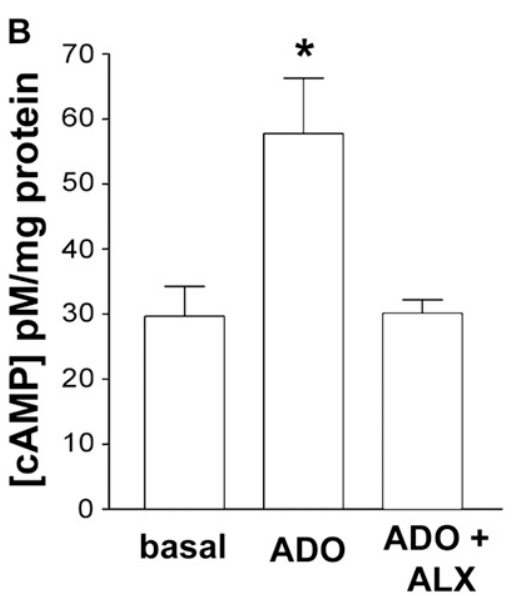

\section{DISCUSSION}

Precise regulation of ASL height (volume) is crucial for maintaining mucus clearance and for keeping the lungs free from bacterial and viral infections. We have previously found that ADO must be present in the ASL for normal ASL homeostasis and mucus transport (37). However, the underlying ADO receptor has not been identified. Here we demonstrate both molecularly and functionally that the $\mathrm{A}_{2 \mathrm{~B}}-\mathrm{R}$ is the main $\mathrm{ADO}$

Figure 4. The Effect of ADO on HBEC intracellular signaling. (A) Mean ratios of emission from airway cultures loaded with Fura-2-AM and excited at 340 and $380 \mathrm{nM}$ after ADO and ATP addition $(n=6)$. (B) Mean intracellular CAMP concentrations under basal conditions, after ADO addition, and after ADO of $10^{-5} \mathrm{M}$ alloxazine. Data shown as mean \pm SEM. ${ }^{*} P<0.05$ compared with nonstimulated cultures. addition in the presence

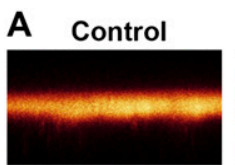

ZM241385
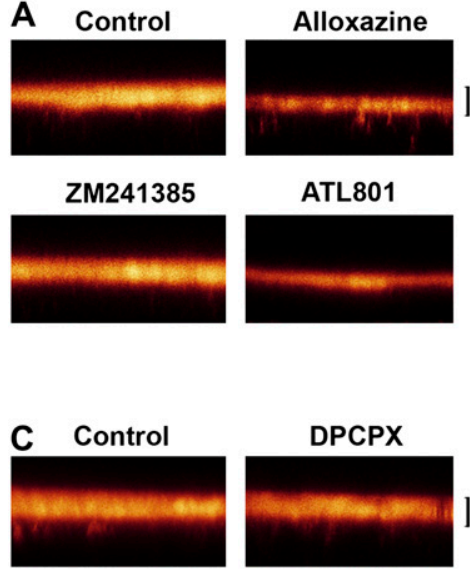

MRS1191

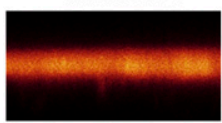

DPCPX

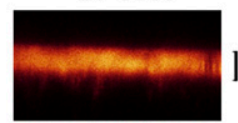

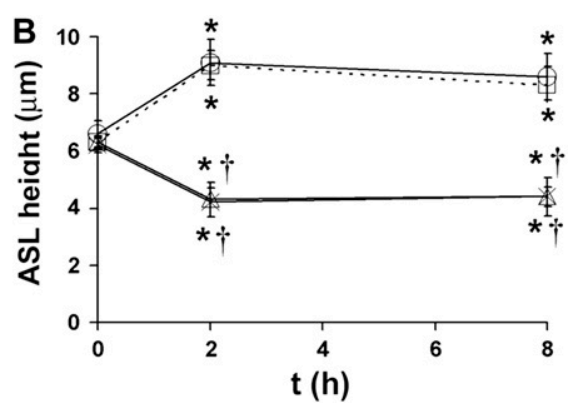

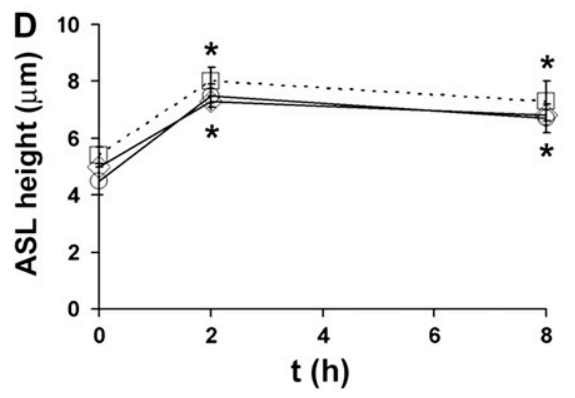

A

B
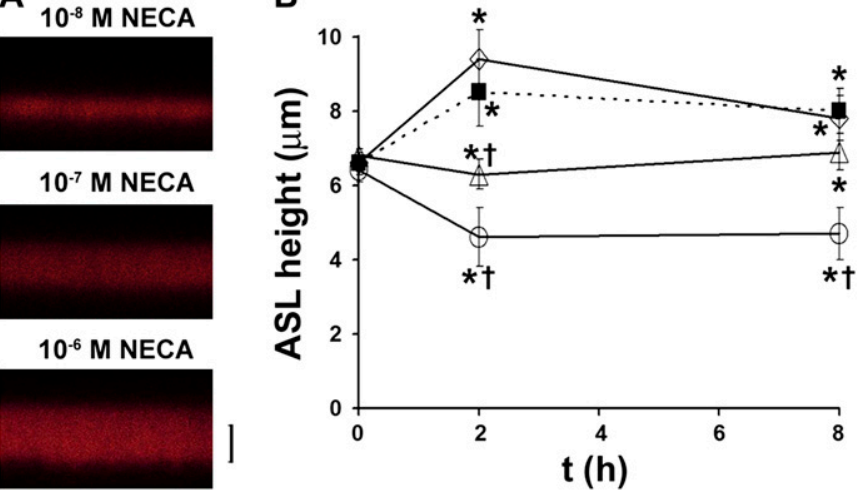

Figure 5. Micromolar levels of the ADO analog NECA are required to reprise ASL volume homoestasis. $(A) X Z$ confocal images of ASL labeled with FITC-dextran (red) 8 hours after addition of PBS containing ADA and NECA. (B) Mean data taken from A. Squares, control; circles, ADA and $10^{-8} \mathrm{NECA}$; triangles, $\mathrm{ADA}$ and $10^{-7} \mathrm{M} \mathrm{NECA}$; diamonds, $\mathrm{ADA}$ and $10^{-6} \mathrm{M} \mathrm{NECA}$. All $n=7$. ${ }^{*} p<0.05$ to $\mathrm{t}=0 .{ }^{\dagger} p<0.05$ to control samples at that time point. Scale bar is $7 \mu \mathrm{m}$.

receptor subtype expressed in human bronchial epithelia. Stimulation of this receptor with ADO increases $\mathrm{Cl}^{-}$secretion in vivo, and results in a dose-dependent increase in $\mathrm{Cl}^{-}$secretion in vitro that is accompanied by an increase in cAMP but not $\mathrm{Ca}^{2+}$, suggesting that this receptor is linked to $\mathrm{G}_{\mathrm{s}}$, rather than $\mathrm{G}_{\mathrm{q}}$. This is an $\mathrm{A}_{2 \mathrm{~B}}-\mathrm{R}$-mediated response and chronic stimulation of this receptor appears to be a crucial aspect of ASL volume regulation, and inhibition of $\mathrm{A}_{2 \mathrm{~B}}-\mathrm{R}$ results in CF-like ASL volume depletion.

We found that the $A_{2 B}-R$ was the most highly expressed ADO-R in freshly obtained human bronchial epithelium, and that ADO addition activated CFTR-mediated $\mathrm{Cl}^{-}$secretion in vivo (Figures 1 and 2). ADO measured by lavage in vivo was approximately $740 \mathrm{nM}$, and since the $\mathrm{EC}_{50}$ for the $\mathrm{A}_{2 \mathrm{~B}}-\mathrm{R}$ is approximately 1 to $2 \mu \mathrm{M}$, this amount of endogenous ADO would be predicted to activate the $\mathrm{A}_{2 \mathrm{~B}}-\mathrm{R}$ by approximately $25 \%$ in vivo. Pretreatment with caffeine attenuated this activation

Figure 6. Autoregulation of ASL height is abolished by the addition of $\mathrm{A}_{2 \mathrm{~B}}$-R-specific antagonists to the ASL. ( $A$ ) $X Z$ confocal images of ASL labeled with FITC-dextran (red) 8 hours after addition of PBS containing vehicle or ADO-R antagonists. (B) Mean ASL height with time under control conditions (dotted lines, squares) versus in the presence of ATL801 (crosses, $300 \mathrm{nM} ; n=5$ ), ZM241385 (circles), and alloxazine (triangles) (both preadded at $\left.10^{-6} \mathrm{M}\right)$. (C) XZ confocal images of ASL 8 hours after addition of PBS containing vehicle or ADO-R antagonists. (D) Mean ASL height with time under control conditions (dotted lines) and in the presence of DPCPX (diamonds) and MRS1191 (circles) (both at 10-6 M). All $n=6$. ${ }^{*} p<0.05$ to $\mathrm{t}=0 .{ }^{\dagger} p<0.05$ to control samples at that time point. Scale bar is $7 \mu \mathrm{m}$. 
(Figure 2). Caffeine is a nonspecific ADO-R antagonist and we cannot exclude the possibility that this activation was mediated by $A_{2 A}-R$. However, $A_{2 A}-R$ is thought to be serosally located in the airway epithelia and may not have been activated during our nasal PD experiments (38). Caffeine can also act as a phosphodiesterase inhibitor, which could raise cAMP and confound our results. However, at low $\mu \mathrm{M}$ concentrations caffeine does not alter CFTR activity, suggesting that this concentration is insufficient to alter phosphodiesterase activity and that the observed effects were purely due to the inhibitory effects of caffeine on ADO-R (28).

Both A1-R and A3-R have been detected in airway epithelia. For example, McCoy and coworkers showed that inhibition of A1-R increased cAMP and stimulated a $\mathrm{Cl}^{-}$conductance in immortalized normal and CF cell lines, as well as in CF nasal polyps (39). In addition, McNamara and colleagues found that $\mathrm{A}_{1}-\mathrm{R}$ were present in airway epithelia and that stimulation of these receptors increased intracellular $\mathrm{Ca}^{2+}$ and mucus production (40). We did not detect A1-R by RT-PCR, and we also found no change in $\mathrm{Ca}^{2+}{ }_{\mathrm{i}}$ upon ADO-addition. However, McNamara and coworkers used airway cells obtained from Clonetics, Inc. that had been passaged several times to increase cell numbers before culturing, raising the possibility that their phenotype had been changed by the extensive passaging (40). While we cannot exclude the possibility that our HBECs have also begun to change their phenotype during culturing as compared with the native tissue, we cultured our cells immediately after isolation from donor lungs to minimize this eventuality.

$\mathrm{A}_{2 \mathrm{~A}}-\mathrm{R}$ have also been described in bronchial epithelial cell lines and bovine trachea, where they stimulate wound healing (41). To date, A2A-R have not been shown to regulate airways ion transport and in CALU3 cells, where ADO activates CFTR, $\mathrm{A}_{2 \mathrm{~A}}-\mathrm{R}$ were thought to be basolateral and not involved in ion transport (38).

The $A_{2 B}-R$ has been implicated in regulation of CFTR and $\mathrm{Cl}^{-}$secretion by several groups both using cell lines such as CALU3s $(23,42)$ and in primary nasal cultures $(43)$. Based on our PCR data and our inhibitor studies, this also appears to be the case in bronchial epithelia. We found no effect of ZM241385 on ASL height (Figures 3 and 6), unlike ATL801 exposure, which consistently inhibited ASL volume homeostasis (Figure 3 and 6). However, Linden and coworkers have reported that ZM241385 also blocks $A_{2 B}-R$ in the micromolar range (44), suggesting that this compound may have tissue-specific activities.

We have previously reported that ASL ADO concentrations are approximately $100 \mathrm{nM}$ in our $\operatorname{HBECs}(5,18)$. This is lower than what has previously been measured by bronchoalveolar lavage (20), and this difference may reflect the absence of airflowinduced shear stress, which can drive ATP release and ADO formation. Also, since macrophages are absent from our culture system, their contribution to ASL ADO is not accounted for. Further, we have not been able to directly measure ASL ADO at the epithelial surface, and our estimates are based on measurements of ADO in bulk solution (i.e., $\sim 50 \mu$ l of PBS added to culture surfaces rather than true "thin film" conditions). ATP has previously been shown to be 2 to $3 \log$ units higher at the cell surface than in lavage using luciferase attached to the cell surface, and this phenomenon may occur with other molecules such as ADO (45).

To gain an appreciation of the ADO concentration required to regulate ASL volume, we replaced ASL with test solutions containing ADA to remove any endogenous ADO in the presence of the nonhydrolysable ADO analog NECA. ADA addition with $10^{-8} \mathrm{M}$ NECA caused a rapid $(<2 \mathrm{~h})$ depletion of
ASL volume to minimal levels, while addition of $10^{-7} \mathrm{M}$ NECA with ADA caused neither absorption nor secretion, and $10^{-6}$ NECA with ADA caused ASL height to increase in a similar fashion to cultures exposed to PBS alone. NECA is approximately 10 times more potent than $A D O$ for the $A_{2 B}-R$, so these data suggest that if 0.1 to $1 \mu \mathrm{M}$ NECA is required to regulate ASL volume, then the cell surface ADO concentration must be approximately 1 to $10 \mu \mathrm{M}$ in native ASL to activate $A_{2 B}-R$, stimulate CFTR and maintain ASL volume appropriately. Based on our dose response to ADO for $\mathrm{Cl}^{-}$secretion (Figure 3B), this concentration of $A D O$ would be sufficient to activate the $A_{2 B}-R$ and regulate ASL height and is consistent with A2B-R inhibition causing a collapse of ASL volume (Figures 6A and 6B).

Based on data showing that $\mathrm{ADO}$ is raised in chronic lung diseases $(12,13)$ and that pharmacological inhibition of $A_{2 B}-R$ in mice reduces inflammation $(11,46)$, the blockade of $A_{2 B}-R$ has been proposed as a treatment for inflammation in chronic lung disease. However, while there is undeniably a link between $\mathrm{ADO}$ and inflammation, recent studies using $\mathrm{A}_{2 \mathrm{~B}}-\mathrm{R}$ knockout mice have suggested that A2B-R is anti-inflammatory $(47,48)$. Furthermore, CFTR expression is not essential in murine airways, as shown by the lack of lung phenotype in CF mice (49), and so the inhibition of $\mathrm{A}_{2 \mathrm{~B}}-\mathrm{R}$ and subsequent CFTR disregulation would not be expected to have any measurable effect on murine airway phenotype. We and others have proposed that the $A_{2 B}-R$ regulates CFTR in human airways $(15,18,23,50)$, suggesting that $\mathrm{A}_{2 \mathrm{~B}}-\mathrm{R}$ inhibition may dangerously impinge upon CFTR regulation in vivo. Thus, based on our emerging understanding of $\mathrm{A}_{2 \mathrm{~B}}-\mathrm{R}-\mathrm{CFTR}$ signaling, we propose that chronic addition of $\mathrm{A}_{2 \mathrm{~B}}-\mathrm{R}$ antagonists to subjects without $\mathrm{CF}$ could inhibit CFTR-mediated ASL volume homeostasis, accentuating mucus accumulation in COPD or asthma. In contrast, $\mathrm{A}_{2 \mathrm{~B}}-\mathrm{R}$ antagonists may be beneficial in CF lung disease: $\mathrm{ENaC}$ is positively regulated by cAMP in the absence of CFTR (19), so $A_{2 B}-R$ inhibition may be therapeutically useful in damping down $\mathrm{ENaC}$-led hyperabsorption in addition to any inhibitory effects on $\mathrm{A}_{2 \mathrm{~B}}-\mathrm{R}$-induced inflammation.

In conclusion, we find that the $\mathrm{A}_{2 \mathrm{~B}}-\mathrm{R}$ is the only $\mathrm{ADO}$ receptor expressed in primary bronchial epithelial cultures, and despite its insensitivity to ADO relative to other ADO-Rs, chronic activation of this receptor is required for ASL volume homeostasis. It is likely that the cell surface ADO concentration is greater than can be measured by lavage and that airway epithelia sense the concentration of ADO to regulate CFTR activity, and that this action occurs in parallel with regulation of ENaC by CFTR and by extracellular proteases and protease inhibitors (21). Factors that change ADO in the airways, such as shear stress (14) or additional release of nucleotides or ADA from macrophages, will likely have profound effects on CFTR regulation and ASL volume homeostasis. The relative lack of sensitivity to ADO, and the lack of desensitization of the receptor after stimulation (51), may be required to maintain a relatively constant response (i.e., continued production of ASL and ciliary beating) despite potentially fluctuating ADO levels. Morse and coworkers have also shown that ADO also increases ciliary beating through $\mathrm{A}_{2 \mathrm{~B}}-\mathrm{R}$ (52). Thus, this receptor appears geared to chronically maintain the mucus clearance component of the innate lung defense system and the increase in ADO seen in chronic airway diseases may in part be a compensatory mechanism to increase mucus clearance by increasing ASL hydration and ciliary beat frequency.

Conflict of Interest Statement: R.T. received a grant from BAT for $\$ 647,000$ to study the effects of cigarette smoke on CFTR function airway epithelia. No money from this grant was used in this study, and this study was paid for by grant R01 HL074158. R.T. also has a separate area of research, looking at the effects of estrogen on airway epithelial function, that is funded by the Cystic Fibrosis 
Foundation. L.A.C. has co-filed a patent on the effects of tamoxifen on P2Y2mediated airway secretion which is currently pending. S.H.D. has an industry sponsored grant from Inspire Pharmaceuticals for $\$ 127,227$ in 2007-2008. None of the other authors has a financial relationship with a commercial entity that has an interest in the subject of this manuscript.

Acknowledgments: The authors gratefully acknowledge the technical assistance of Catja van Heusen and Michael Watson and the help of the UNC CF Center Molecular, Nucleotide and Histology and Tissue Cores. The authors thank Dr. Stephen Tilley for critically reading this manuscript. The kind gift of ATL801 from Adenosine Therapeutics Inc. is also greatly appreciated.

\section{References}

1. Maestrelli P, Saetta M, Mapp CE, Fabbri LM. Remodeling in response to infection and injury: airway inflammation and hypersecretion of mucus in smoking subjects with chronic obstructive pulmonary disease. Am J Respir Crit Care Med 2001;164:S76-S80.

2. Spicuzza L, Di Maria G, Polosa R. Adenosine in the airways: implications and applications. Eur J Pharmacol 2006;533:77-88.

3. Holgate ST. The quintiles prize lecture 2004: the identification of the adenosine a2b receptor as a novel therapeutic target in asthma. $\mathrm{Br} \mathrm{J}$ Pharmacol 2005;145:1009-1015.

4. Varani K, Caramori G, Vincenzi F, Adcock I, Casolari P, Leung E, Maclennan S, Gessi S, Morello S, Barnes PJ, et al. Alteration of adenosine receptors in patients with chronic obstructive pulmonary disease. Am J Respir Crit Care Med 2006;173:398-406.

5. Lazarowski ER, Tarran R, Grubb BR, van Heusden CA, Okada S, Boucher RC. Nucleotide release provides a mechanism for airway surface liquid homeostasis. J Biol Chem 2004;279:36855-36864.

6. Picher M, Burch LH, Hirsh AJ, Spychala J, Boucher RC. Ecto 5'nucleotidase and nonspecific alkaline phosphatase: two amp-hydrolyzing ectoenzymes with distinct roles in human airways. J Biol Chem 2003; 278:13468-13479.

7. Bucheimer RE, Linden J. Purinergic regulation of epithelial transport. J Physiol 2004;555:311-321.

8. Fredholm BB, Arslan G, Halldner L, Kull B, Schulte G, Wasserman W. Structure and function of adenosine receptors and their genes. Naunyn Schmiedebergs Arch Pharmacol 2000;362:364-374.

9. Zhong $\mathrm{H}, \mathrm{Wu} \mathrm{Y}$, Belardinelli L, Zeng D. A2b adenosine receptors induce IL-19 from bronchial epithelial cells and results in TNF- $\alpha$ increase. Am J Respir Cell Mol Biol 2006;35:587-592.

10. Blackburn MR, Lee CG, Young HW, Zhu Z, Chunn JL, Kang MJ, Banerjee SK, Elias JA. Adenosine mediates IL-13-induced inflammation and remodeling in the lung and interacts in an IL-13adenosine amplification pathway. J Clin Invest 2003;112:332-344.

11. Sun CX, Zhong H, Mohsenin A, Morschl E, Chunn JL, Molina JG, Belardinelli L, Zeng D, Blackburn MR. Role of a(2b) adenosine receptor signaling in adenosine-dependent pulmonary inflammation and injury. J Clin Invest 2006;116:2173-2182.

12. Mohsenin A, Blackburn MR. Adenosine signaling in asthma and chronic obstructive pulmonary disease. Curr Opin Pulm Med 2006;12:54-59.

13. Polosa R, Holgate ST. Adenosine receptors as promising therapeutic targets for drug development in chronic airway inflammation. Curr Drug Targets 2006;7:699-706.

14. Tarran R, Button B, Boucher RC. Regulation of normal and cystic fibrosis airway surface liquid volume by phasic shear stress. Annu Rev Physiol 2006;68:543-561.

15. Hentchel-Franks K, Lozano D, Eubanks-Tarn V, Cobb B, Fan L, Oster $\mathrm{R}$, Sorscher E, Clancy JP. Activation of airway Cl- secretion in human subjects by adenosine. Am J Respir Cell Mol Biol 2004;31:140-146.

16. Huang P, Gilmore E, Kultgen P, Barnes P, Milgram S, Stutts MJ. Local regulation of cystic fibrosis transmembrane regulator and epithelial sodium channel in airway epithelium. Proc Am Thorac Soc 2004;1:33-37.

17. Chambers LA, Constable M, Clunes MT, Olver RE, Ko WH, Inglis SK, Wilson SM. Adenosine-evoked $\mathrm{Na}+$ transport in human airway epithelial cells. Br J Pharmacol 2006;149:43-55.

18. Tarran R, Button B, Picher M, Paradiso AM, Ribeiro CM, Lazarowski ER, Zhang L, Collins PL, Pickles RJ, Fredberg JJ, et al. Normal and cystic fibrosis airway surface liquid homeostasis: the effects of phasic shear stress and viral infections. J Biol Chem 2005;280:35751-35759.

19. Knowles MR, Boucher RC. Mucus clearance as a primary innate defense mechanism for mammalian airways. J Clin Invest 2002;109: 571-577.

20. Driver AG, Kukoly CA, Ali S, Mustafa SJ. Adenosine in bronchoalveolar lavage fluid in asthma. Am Rev Respir Dis 1993;148:91-97.

21. Tarran R, Trout L, Donaldson SH, Boucher RC. Soluble mediators, not cilia, determine airway surface liquid volume in normal and cystic fibrosis superficial airway epithelia. J Gen Physiol 2006;127: 591-604.

22. Southern KW, Noone PG, Bosworth DG, Legrys VA, Knowles MR, Barker PM. A modified technique for measurement of nasal transepithelial potential difference in infants. J Pediatr 2001;139:353-358.

23. Huang P, Lazarowski ER, Tarran R, Milgram SL, Boucher RC, Stutts MJ. Compartmentalized autocrine signaling to cystic fibrosis transmembrane conductance regulator at the apical membrane of airway epithelial cells. Proc Natl Acad Sci USA 2001;98:14120-14125.

24. Matsui H, Grubb BR, Tarran R, Randell SH, Gatzy JT, Davis CW, Boucher RC. Evidence for periciliary liquid layer depletion, not abnormal ion composition, in the pathogenesis of cystic fibrosis airways disease. Cell 1998;95:1005-1015.

25. Tarran R, Loewen ME, Paradiso AM, Olsen JC, Gray MA, Argent BE, Boucher RC, Gabriel SE. Regulation of murine airway surface liquid volume by CFTR and Ca2+-activated Cl-conductances. J Gen Physiol 2002;120:407-418.

26. Kreda SM, Mall M, Mengos A, Rochelle L, Yankaskas J, Riordan JR, Boucher RC. Characterization of wild-type and deltaf508 cystic fibrosis transmembrane regulator in human respiratory epithelia. Mol Biol Cell 2005;16:2154-2167.

27. Boucher RC. Human airway ion transport: part one. Am J Respir Crit Care Med 1994;150:271-281.

28. Becq F, Jensen TJ, Chang XB, Savoia A, Rommens JM, Tsui LC, Buchwald M, Riordan JR, Hanrahan JW. Phosphatase inhibitors activate normal and defective cftr chloride channels. Proc Natl Acad Sci USA 1994;91:9160-9164.

29. Fredholm BB, Irenius E, Kull B, Schulte G. Comparison of the potency of adenosine as an agonist at human adenosine receptors expressed in Chinese hamster ovary cells. Biochem Pharmacol 2001; 61:443-448.

30. Naganuma M, Wiznerowicz EB, Lappas CM, Linden J, Worthington MT, Ernst PB. Cutting edge: critical role for a2a adenosine receptors in the t cell-mediated regulation of colitis. J Immunol 2006;177:2765-2769.

31. Cacciari B, Pastorin G, Spalluto G. Medicinal chemistry of a2a adenosine receptor antagonists. Curr Top Med Chem 2003;3:403-411.

32. Coates J, Sheehan MJ, Strong P. 1,3-dipropyl-8-cyclopentyl xanthine (dpcpx): a useful tool for pharmacologists and physiologists? Gen Pharmacol 1994;25:387-394.

33. Jacobson KA. Adenosine a3 receptors: novel ligands and paradoxical effects. Trends Pharmacol Sci 1998;19:184-191.

34. Sheppard DN, Welsh MJ. Effect of atp-sensitive $\mathrm{k}+$ channel regulators on cystic fibrosis transmembrane conductance regulator chloride currents. J Gen Physiol 1992;100:573-591.

35. Winpenny JP, McAlroy HL, Gray MA, Argent BE. Protein kinase C regulates the magnitude and stability of CFTR currents in pancreatic duct cells. Am J Physiol 1995;268:C823-C828.

36. Klinger M, Freissmuth M, Nanoff C. Adenosine receptors: G proteinmediated signalling and the role of accessory proteins. Cell Signal 2002;14:99-108.

37. Chambers LA, Rollins BM, Tarran R. Liquid movement across the surface epithelium of large airways. Respir Physiolo Neurobiol 2007; 159:256-270.

38. Szkotak AJ, Ng AM, Man SF, Baldwin SA, Cass CE, Young JD, Duszyk M. Coupling of CFTR-mediated anion secretion to nucleoside transporters and adenosine homeostasis in calu-3 cells. J Membr Biol 2003; 192:169-179.

39. McCoy DE, Schwiebert EM, Karlson KH, Spielman WS, Stanton BA. Identification and function of a1 adenosine receptors in normal and cystic fibrosis human airway epithelial cells. Am J Physiol 1995;268: C1520-C1527.

40. McNamara N, Gallup M, Khong A, Sucher A, Maltseva I, Fahy J, Basbaum C. Adenosine up-regulation of the mucin gene, muc2, in asthma. FASEB J 2004;18:1770-1772.

41. Allen-Gipson DS, Wong J, Spurzem JR, Sisson JH, Wyatt TA. Adenosine a2a receptors promote adenosine-stimulated wound healing in bronchial epithelial cells. Am J Physiol Lung Cell Mol Physiol 2006; 290:L849-L855.

42. Cobb BR, Fan L, Kovacs TE, Sorscher EJ, Clancy JP. Adenosine receptors and phosphodiesterase inhibitors stimulate $\mathrm{Cl}$ - secretion in calu-3 cells. Am J Respir Cell Mol Biol 2003;29:410-418.

43. Lazarowski ER, Mason SJ, Clarke L, Harden TK, Boucher RC. Adenosine receptors on human airway epithelia and their relationship to chloride secretion. Br J Pharmacol 1992;106:774-782.

44. Linden J, Thai T, Figler H, Jin X, Robeva AS. Characterization of human $\mathrm{a}(2 \mathrm{~b})$ adenosine receptors: radioligand binding, Western 
blotting, and coupling to $\mathrm{g}(\mathrm{q})$ in human embryonic kidney 293 cells and hmc-1 mast cells. Mol Pharmacol 1999;56:705-713.

45. Okada SF, Nicholas RA, Kreda SM, Lazarowski ER, Boucher RC. Physiological regulation of atp release at the apical surface of human airway epithelia. $J$ Biol Chem 2006.

46. Mustafa SJ, Nadeem A, Fan M, Zhong H, Belardinelli L, Zeng D. Effect of a specific and selective $a(2 b)$ adenosine receptor antagonist on adenosine agonist amp and allergen-induced airway responsiveness and cellular influx in a mouse model of asthma. J Pharmacol Exp Ther 2007;320:1246-1251.

47. Hua X, Kovarova M, Chason KD, Nguyen M, Koller BH, Tilley SL. Enhanced mast cell activation in mice deficient in the a2b adenosine receptor. J Exp Med 2007;204:117-128.

48. Yang D, Zhang Y, Nguyen HG, Koupenova M, Chauhan AK, Makitalo M, Jones MR, St Hilaire C, Seldin DC, Toselli P, et al. The a2b adenosine receptor protects against inflammation and excessive vascular adhesion. J Clin Invest 2006;116:1913-1923.

49. Snouwaert JN, Brigman KK, Latour AM, Malouf NN, Boucher RC, Smithies O, Koller BH. An animal model for cystic fibrosis made by gene targeting. Science 1992;257:1083-1088.

50. Clancy JP, Ruiz FE, Sorscher EJ. Adenosine and its nucleotides activate wild-type and $\mathrm{r} 117 \mathrm{~h}$ CFTR through an a2b receptor-coupled pathway. Am J Physiol 1999;276:C361-C369.

51. Sitaraman SV, Si-Tahar M, Merlin D, Strohmeier GR, Madara JL. Polarity of $\mathrm{a} 2 \mathrm{~b}$ adenosine receptor expression determines characteristics of receptor desensitization. Am J Physiol Cell Physiol 2000;278: C1230-C1236.

52. Morse DM, Smullen JL, Davis CW. Differential effects of UTP, ATP, and adenosine on ciliary activity of human nasal epithelial cells. Am J Physiol Cell Physiol 2001;280:C1485-C1497. 